\title{
A formal approach to reanalysis: The case of a negative counterfactual marker
}

\author{
Elitzur A. Bar-Asher Siegal*
}

\begin{abstract}
This paper proposes a formal definition of reanalysis, while emphasizing the importance of the distinction between two different kinds of reanalysis: those in which the change is confined to the grammatical level, and those in which it is confined to the semantic level. After tracing the history of a negative counterfactual conditional marker in Hebrew and Aramaic which underwent both syntactic and semantic reanalyses, the paper assesses the concept of reanalysis with focus on the following questions: Is reanalysis a single, clearly-defined phenomenon, and if so, what is its nature? Is it merely a descriptive label for a certain observable state of affairs, or does it explain diachronic changes? Alternatively, perhaps it is a theoretical constraint, a theoretical requirement that linguistic change must be associated with specific environments where reanalysis can take place? A detailed analysis of the marker and its evolution yields the following broad hypothesis: Reanalysis of a linguistic form does not change the truth conditions of the proposition that contains it, regardless of whether the reanalysis is on the grammatical level or on the semantic level.
\end{abstract}

Keywords. reanalysis; historical linguistics; formal diachronic semantics; negative counterfactuals

1. Introduction. Reanalysis is often defined in the following terms:

"A mechanism which changes the underlying structure of a syntactic pattern and which does not involve any immediate or intrinsic modification of its surface manifestation.” (Harris and Campbell 1995: 61, based on Langacker 1977)

According to this definition, reanalysis involves a syntactic change that, at least initially, has no phonological manifestation. Moreover, it constitutes the mechanism that creates such syntactic changes. This paper examines whether the above definition exhaustively captures the phenomenon under discussion, and especially whether reanalysis itself should be characterized as the mechanism that gives rise to the historical linguistic change. After reviewing the main theoretical questions that have been posed in the literature about reanalysis (Section 2), it examines some of them by addressing the development of a specific counterfactural conditional marker in Hebrew and in Aramaic (Sections 3,6), and tracing various syntactic (Section 4) and semantic (Section 5) reanalyses it underwent, which produced somewhat unusual semantic features. Scrutinizing the diachronic changes yields a variety of insights regarding the various types of reanalyses.

2. Reanalysis. The definition of reanalysis quoted above is somewhat problematic in that it focuses on "structural" changes. This is vague; it is not totally clear what does and does not count as a structure; moreover, reanalysis can give rise to semantic changes not only structural ones. But before examining this further, let me review some of the theoretical issues that have recently been raised in the context of reanalysis.

\footnotetext{
*Thanks to Nora Boneh and Noa Bassel for commenting on an early version of this paper. Author: Elitzur A. Bar-
} Asher Siegal, Language, Logic and Cognition Center, The Hebrew University of Jerusalem (ebas@mail.huji.ac.il). 
A review of the studies that address reanalysis reveals that they have taken different and even opposite perspectives on this phenomenon and its essential nature (see Madariaga 2017 for a recent review of the literature on reanalysis). Some regard reanalysis as one of the mechanisms or processes that produce change in languages. If reanalysis is indeed an independent linguistic mechanism or process, the question is whether it is possible to identify some specific factor or factors that trigger it. In other words, are there particular reasons or conditions that cause this process to occur? A positive answer to the last question would suggest that reanalysis should usually be unidirectional: if certain factors trigger a reanalysis of structure $X$ as structure $Y$, we would not expect the same factors to also motivate the reverse reanalysis.

However, a close examination of the motivations for and sources of reanlysis led this concept to undergo a sort of reduction: some scholars came to regard cases of reanalysis as specific instances of more general phenomena, such as analogy (de Smet 2009, 2014 and Kiparsky 2012) or even wider processes of historical change. ${ }^{1}$ Kiparsky (2012) and Garrett (2012), for example, argue that the distinction between reanalysis and grammaticalization has become increasingly harder to maintain. Consequently, an alternative approach minimizes the importance of reanalysis, treating it at most as a convenient descriptive lable. According to this approach, the claim that some linguistic structure underwent reanalysis does not explain the change, but merely describes a situation where the same phrase has two different structures in two historical stages of the same language (McDaniels 2003). From this perspective, reanalysis is just the result of a process that does not, in itself, require an explaination. It happens simply because it can.

Some researchers have described reanalysis as a "mistake", in the sense of language acquisition: language learners misinterpreted a phrase and assigned it a new analysis (neoanalysis). ${ }^{2}$ Researchers who took this view adopted Andersen's (1973) model of historical change, which spoke of "abduction": a process of generalization from facts, and in the case of reanalysis, a generalization of rules which creates rules somewhat different from those that existed before. In practical terms, the approach that addresses reanalysis in terms of language acquisition is not very different from the one that regards it as a description of a process, rather than a historical mechanism.

This last point gives rise to another pivotal question. Reanalysis associates a specific phonological sequence with a new analysis. This raises the question: What is the source of the new analysis? Was the sequence originally ambiguous? ${ }^{3}$ Must the new analysis be somehow available to speakers, deriving from another language they speak, from some other phenomenon within the same language, or from an innate linguistic principle? Incidentally, if reanalysis is anchored in the availability of two competing analyses, one would actually expect it to be reversable, so that if structure $X$ is reanalysed as structure $Y, Y$ can also be reanalyzed as $X$.

Another point worth mentioning is that, whereas historical linguists have often focused on reanalysis involving grammatical change, in Formal Diachronic Semantics, the focus has been on

\footnotetext{
${ }^{1}$ Kiparsky (2012), for example, invokes the principles of simplicity and optimalization.

${ }^{2}$ Andersen (2001b, p. 213, n. 3) suggested using the term "neoanalysis/neanalysis" instead of "reanalysis", and various scholars, such as Felser (2017), adopted this suggestion.

${ }^{3}$ The claim that reanalysis requires an original state of ambiguity is made by Timberlake (1977). See Harris and Campbell (1995: 70-72) for a discussion of its validity. Felser (1917) also addresses the role of ambiguity in historical language change.
} 
semantic shifts motivated by various independent factors, ${ }^{4}$ emphasizing that both the original structure and the new one (produced by reanalysis) are compositionally related to their meanings. This is in fact the essence of reanalysis in this research framework. According to this approach, reanalysis is to a large extent a methodological necessity, a necessary conceptual corollary of assumptions regarding the nature of language and of linguistic signs, and it is a result of independent semantic shifts.

These discussions lead me to assess the concept of reanalysis, focusing on two questions:

1. Is reanalysis one clearly-defined phenomenon?

2. What is the nature of this phenomenon? Is it merely a descriptive label for a certain state of affairs, or does it explain the change? Or perhaps it is a theoretical constraint, a theoretical requirement stipulating that linguistic change must be associated with an environment where reanalysis can take place?

To answer these questions, let me first of all introduce a formal description of reanalysis (BarAsher Siegal 2020b: 22). This formalization may seem similar in its import to descriptions that characterize reanalysis as the result of a process. But, as we shall see, this does not preclude looking for the reasons that motivate the relevant processes. This formalization allows us to characterize the phenomenon itself, even before settling questions regarding its nature, and I will later show that it also forms a basis for addressing a wide range of phenomena in a nuanced manner.

The point of departure for the proposed formalization is a basic understanding of language as a semiotic system anchored in a grammar. According to this approach, for a phonemic sequence $\mathrm{F}$ to be part of the langauge, it must have a (syntactic or morphological) structure $\mathrm{G}$, and a meaning $\mathrm{M}$, relevant to the truth conditions of the utterance of which it is part. In reanalysis, according to the classical views of this phenomenon, the signifier, i.e., the phonological component, remains constant (at least initially), while changes occur on the grammatical and semantic levels. According to this, the formalization of reanalysis is straightforward. As shown in Figure 1, a reanalysis of a string of phonemes $F$ involves cases in which $F$ is associated with two different pairings of structure and meaning $\{\mathrm{G}, \mathrm{M}\}$ at two different points in time ( $\mathrm{t} 1$ and $\mathrm{t} 2$ ). Reanalysis can involve both the morphological/syntactic level and the semantic level (Scenario 1), or alternatively be restricted to one level (Scenarios 2-3).

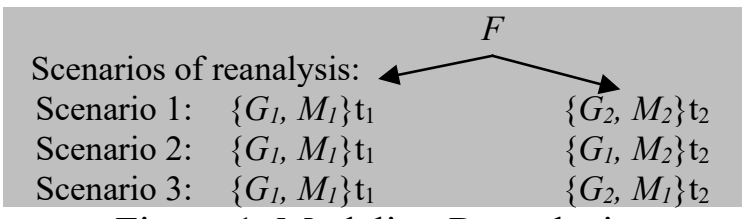

Figure 1. Modeling Reanalysis

In light of this definition, it is pertinent to focus on the following question: Is there a difference between reanalysis confined to the structural level (Scenario 3) and reanalysis confined to the semantic level (Scenario 2)? To tackle this question, let us take a look at the form 'ilmale in

\footnotetext{
${ }^{4}$ For example, Eckardt (2006) follows Traugott \& Dasher (2002) in postulating that the semantic changes involve pragmatic meanings that become integrated in the semantic meaning. According to this view, reanalysis is a reaction to a semantic shift that occurred for independent reasons.
} 
Hebrew and Aramaic, which underwent both structural and semantic reanalysis, and examine them as test cases for the various phenomena involved in reanalysis.

3. The puzzle. The syntactic and semantic evolution of the form 'ilmale in Hebrew and Aramaic has been extensively addressed in many studies over the last 140 years (Lambert 1880, Jastrow 1885, Ben-Haim 1952-1953, Segal 1932, Breuer 1987, Bar-Asher Siegal 2019, 2020a and BarZiv Levy forthcoming.) The discussion generally focuses on the two alternate meanings of this form, which can introduce either a positive counterfactual condition ('if only', henceforth PCC) or a negative counterfactual condition ("if not," "were it not for", henceforth NCC). Scholars have long noted that the alternation is not random. Some pointed out that the meaning of this form changed over time, as neatly illustrated by the minimal pair below (Breuer 1987, Bar-Asher Siegal 2019). In (1a), from the Tosefta, written in the earlier Tannaitic period (around the $2^{\text {nd }}$ century C.E), 'ilmale has the negative meaning, whereas in (1b), from the later Babylonian Amoraic literature (around the $5^{\text {th }}-7^{\text {th }}$ centuries), 'ilmale has the positive meaning, and hence must be followed by the negator lo "not".

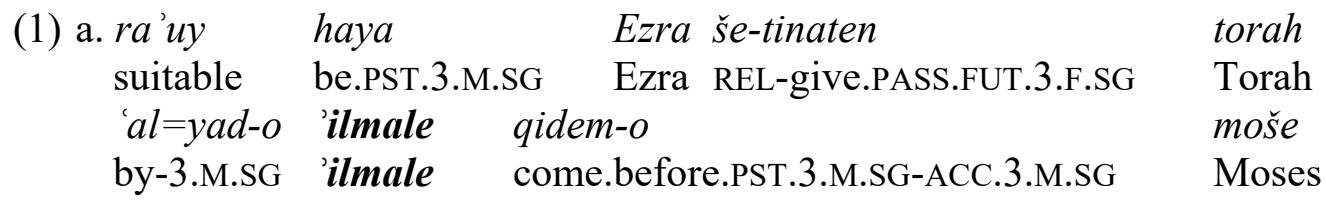

(Tosefta, Sanhedrin 4:7)

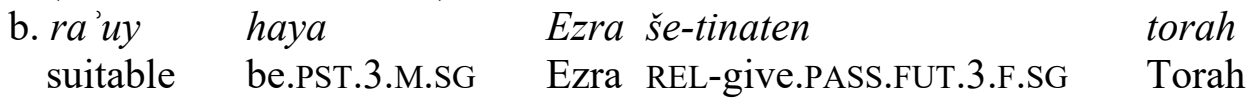

le-yisrael 'al=yad-o 'ilmale lo qidem-o moše

to-Israel by-3.M.SG ilmale NEG come.before.PST.3.M.SG-ACC.3.M.SG Moses

(Babylonian Talmud, Sanhedrin 21b)

'Ezra was suitable for the Torah to be given (to Israel) by him, had Moses not come first.'

( $a$ and $b$ have the same translation)

In addition to this diachronic shift in the meaning of the word, Lambert (1880) and later Segal (1932) noted that, in the Amoraic Babylonian literature (and later also in the Medieval Rabbinic literature), a synchronic distribution pattern can be discerned, wherein the meaning depends on the syntactic environment: when preceding a noun, ilmale takes the NCC meaning, and when preceding a clause, it takes the PCC meaning:

(2) BEFORE A NOUN:

a. Hebrew

'ilmale šabbat, 'en nabi be-roš hodeš

ilmale Sabath, NEG prophet in-head.of month

'If it were not Shabbat, there would be no [reading from] the Prophets on the New Moon.' (Babylonian Talmud, Shabbat 24a)

b. Aramaic

'ilmale targumā d-hay qrā lā hwayād'in-an

'ilmale translation of-this verse NEG be.PAST know.PTCP-1.PL

'Were it not for the translation of this verse, we would not have known what it is saying' (Babylonian Talmud, Megillah 3a) 
a. Hebrew

'ilmale $k \bar{a}$ 'as- $t i \quad$ ale-kem

'ilmale be.angry.PST.1.SG on-2.M.PL

"for had I become angry on you" (Babylonian Talmud, Berachot 7a)

b. Aramaic

$\begin{array}{lll}\text { 'ilmale draš-ah } & \text { 'aher l-hay } & \text { qrā } \\ \text { 'ilmale interpret.PAST.3.M.SG-3.F.SG } & \text { 'aher ACC-DEM.SG } & \text { verse }\end{array}$

'Had Aher interpreted this verse homiletically...'( Babylonian Talmud, Kiddushin 39b).

Bar-Asher Siegal $(2019,2020$ a) outlined eight stages in the diachronic evolution of the conditional form 'ilmale in Hebrew and Aramaic, involving phonological, morphological, syntactic and semantic changes. In this paper, I wish to look further into a crucial stage in the development of 'ilmale, and see what light it can shed on different types of reanalysis. The discussion in this paper will focus on explaining the connection between the meaning of the form and its syntactic environment, as evident in the Babylonian Talmud (e.g., examples 2-3). In my previous study, I stated that the distribution pattern - with one meaning occurring before a noun and another occurring in the beginning of a conditional clause - can be explained as the outcome of bifold diachronic processes: first, a syntactic reanalysis yielding two syntactic environments in which 'ilmale assumed different grammatical functions, and then a semantic reanalysis that occurred in only one of these environments. I will elaborate this explanation and also consider what it may tell us about the nature of reanalysis.

\section{Changes in the grammar and meaning of 'ilmale}

4.1. THE CHANGES. In the Hebrew and Aramaic of the Babylonian Talmud, 'ilmale exhibits the following distribution (exemplified in examples (2-3) above): Before a noun: NCC; Before a clause: PCC. This distribution can be explained as follows:

I. At first, 'ilmale served exclusively as a clause-initial marker introducing NCCs.

Subsequently the following split occurred: When occuring before a noun, 'ilmale was reanalysed as a preposition meaning "without." In clause-initial position, it retained its original meaning and syntactic function ('if not').

II. At a later stage, 'ilmale underwent a semantic shift, whereby its meaning changed from an NCC marker to a PCC marker. For reasons that will be explained below, this change was possible only in environments where this form served as a marker of a conditional clause and not as a preposition.

A detailed stage-by-stage description of this process can shed crucial light on various types of reanalysis.

4.2. SYNTACTIC SPLIT. Following Lambert's (1880) syncronic description, the proposal presented here and assumes that, in the first stage, ilmale underwent a purely grammatical change: before nouns it was reanalysed as a preposition meaning 'without', as in the following example:

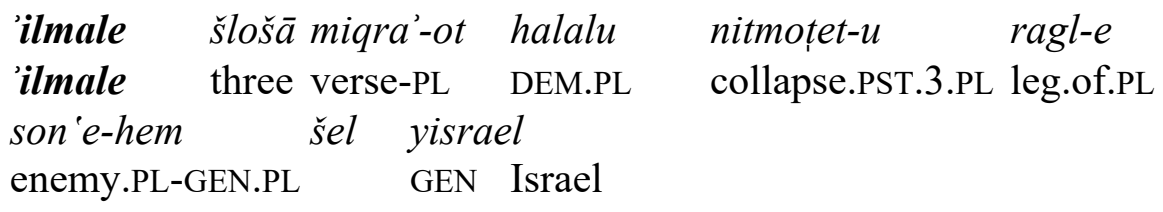


'Were it not for these three verses, the legs of the enemies of the Jewish people would have collapsed' (Babylonian Talmud, Sukkah 52b) [= without these three verses...]

Lambert sufficed with a synchronic presentation of these facts. However, given the assumption (plausible for several reasons, see Bar-Asher Siegal 2019, § 2) that the form 'ilmale originally contained the conditional element ' $i$-, which introduces a negative counterfactual condition clause, it is necessary to explain how a clause-initial conditional marker changed its lexical category to become a preposition. I will show that this involved a total syntactic reanalysis of constructions with prenominal 'ilmale, and then address the question of what may have prompted this transformation.

Returning to Diagram 1 of reanalysis types, when the change is confined to the syntactic level (Scenario 3), the construction produced by reanalysis is semantically equivalent to the original construction. As Bar-Asher Siegal (2015) and Bar-Asher Siegal \& De Clercq (2019) proposed in a different context, the availability of two alternative syntactic analyses, identical in meaning, is likely what enables, and perhaps even motivates, syntactic reanalysis. In our context, the transformation from a conditional marker to a preposition was made possible by the fact the two constructions - an existential condition-clause comprising the components in (5a) and a preposition phrase consisting of "without" and a noun phrase, as in (5b) - are semantically identical:

$$
\begin{aligned}
& \text { a. (connective }+ \text { ) negation }+ \text { existential predicate }+ \text { NP } \\
& \text { b. without }+ \text { NP }
\end{aligned}
$$

This semantic equivalence is illustrated in (6). The counterfactual condition clause in (6a), with an existential predicate, is semantically equivalent to the prepositional phrase in (6b).

(6) a. If there had been no book, David would have failed the test.

b. Without the book, David would have failed the test.

I propose that it is this semantic equivalence that facilitates the syntactic reanalysis. In a previous study, I showed that several prepositions with the privative meaning "without" in Semitic languages, such as the Syriac $d l \bar{a}$, originate in bare existentials, i.e., existential clauses that lack an overt existential predicate and thus include only the NP whose non-existence is being asserted (Bar-Asher Siegal 2011: 78-82). If this is indeed the case, the change of grammatical function demonstrated by ilmale is familiar from other Semitic languages as well. The diagram in (8) shows that, beyond the semantic equivalence, the two constructions (existential clauses introduced by a connective and PPs headed by without) can also be identical in the number of components they contain, since Semitic languages have covert existential predication (Brockelmann 1913, pp. 35-41; Bar-Asher Siegal 2009: 425-431). Similarly, based on a broad cross-linguistic survey, Francez $(2007,2009)$ determined that the pivot is the only part of existential constructions that is universally obligatory, and therefore took bare existentials to be the basic construction. Consequently, he proposes that the pivot is actually the main predicate of existential constructions. Accordingly, in bare existentials, there is saturation by an implicit argument, its scope set, which is a set of entities related by some contextually determined relation to this discourse referent. Thus, (7) represents the semantics of existential predication, where $\tau$ is any simple type, $\mathrm{Q}$ is a relation between sets determined by the determiner of the pivot, and $\mathrm{N}$ is a set determined by the common noun in the pivot:

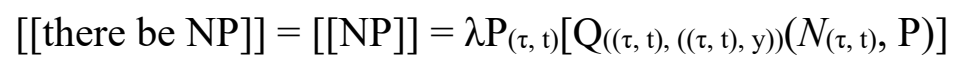


As a result, element $A$, originally a conditional connective introducing an existential conditional clause (Interpretation 1), can be reinterpreted as a preposition (Interpretation 2).

A

\section{Interpretation 1 Connective} Interpretation 2 Preposition
O B

existential predicate $\mathrm{NP}$

$\mathrm{NP}$

In light of the above, it's possible that this process also occurred in sentences featuring 'ilmale:

$\begin{array}{llll} & \text { 'ilmale } & \boldsymbol{\varnothing} & \text { NP } \\ \text { Interpretation } 1 \mathbf{t}_{1} & \text { Connective } & \text { existential predicate } & \text { NP } \\ \text { Interpretation } \mathbf{2} \mathbf{t}_{2} & \text { Preposition } & \text { NP }\end{array}$

According to this analysis, 'ilmale originally had a single meaning and a single grammatical function. When occurring before a noun, it introduced an NCC, and the following noun was understood as the pivot of the existential predication (cf. Brockelmann (1913: 647-648) on Arabic and Rabin (2000: 180, n.2) on ilule in Hebrew). Subsequently, 'ilmale underwent grammatical reanalysis, whereby its grammatical function changed from a conditional marker to a preposition. It thus assumed two different functions with similar meaning: a conditional element meaning 'if not', and a preposition meaning 'without'.

The use of 'ilmale as a preposition is common both in the Hebrew and the Aramaic of the Babylonian Talmud. According to the analysis proposed here, at this stage the reanalysis was purely syntactic and did not affect the semantics at all. Before turning to the further developments of 'ilmale, let us address the implications of this proposal for the broader questions regarding reanalysis that were presented in the introduction. As noted, one of the main questions regarding reanalysis involves the source of the "new interpretation": must it already be "familiar" to speakers in some manner, from an equivalent in another language, from some language-internal constraint, or from innate universal grammar? The discussion below will show that the syntactic transformation of 'ilmale from a conditional marker into a preposition sheds some light on this question.

Until now, I have been translating the prenominal 'ilmale using the preposition without. But this translation is inaccurate, perhaps even misleading. Prenominal 'ilmale in fact is not always interchangeable with the English privative preposition without, for it does not possess the full range of meanings associated with this preposition. In the following sentence, for instance, without cannot be replaced by 'ilmale: 'The boy showed up without a book'. In contrast to without, which is not inherently associated with conditionality, 'ilmale, even as a preposition, always introduces a negative condition. I have been translating it as without because, as noted in dictionaries, ${ }^{5}$ this preposition does have the meaning (or implication) of negative condition in some environments. Adopting Kratzer's semantic analysis of conditionals as consisting of three parts (illustrated in Figure 2), the evolution of 'ilmale can be described as follows: At $t_{1}$ the restrictor was the antecedent of the conditional, and was associated with the structure of the

\footnotetext{
${ }^{5}$ Without - OED:

In senses B. 7 - B. 11 often with conditional implication (mostly with negative, expressed or implied): If one have (or had) not, if there be (or were) not, unless one have or there be, in the absence of, in default of, "supposing the negation or omission of" (Johnson).

"The people believed that without the nobles there was no safety; the nobles believed that without the crown there was no honour".
} 
clause $\left(\mathrm{CP}\right.$, tense etc.); at $\mathrm{t}_{2}$ the function of the restrictor became part of the meaning of the preposition 'ilmale - which functions as the restrictor of its proposition.

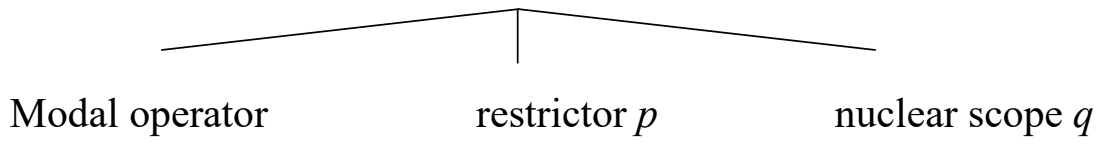

Figure 2. Conditionals à la Kratzer.

The reanalysis of 'ilmale thus produced a unique linguistic item: a preposition confined to contexts that combine the meaning of 'without' with an obligatory component of negative counterfactual condition. Such a meaning is, to the best of my knowledge, not attested in other of the world's languages. The unique meaning of this preposition arises from the possibility of associating a phonetic sequence $F$, paired with a meaning $M$, with two different grammatical structures: an existential clause introduced by a conditional element, and a preposition followed by a noun.

This demonstrates that reanalysis can produce grammatical forms with unusual meanings that may even be unique to a particular language. The characteristics of the product depend on the specific nature of the original and the processes it underwent. The form 'ilmale is not the only example of this; there are additional instances of "unique linguistic beasts" produced via similar processes of reanalysis. Bar-Asher Siegal \& De Clercq (2019) discuss negative elements that emerged independently in Jewish Babylonian Aramaic and Sicilian, whose unique features stem from their historical origin.

Reanalysis, then, does not necessarily reproduce a pattern that already exists in the language or in some other language, but depends on semantic interpretations made available by the grammar of the language in which it occurs. In other words, using the terminology in Table 1, although both syntactic interpretations were available at $t_{1}$, the association between $G_{2}$ and $M_{1}$ at $t_{2}$ is new. Furthermore, the analysis presented here implies that the syntactic reanalysis of 'ilmale was possible precisely because there was no change on the semantic level $\left(M_{1}=M_{2}\right)$. This example and others suggest that syntactic reanalysis will occur more often in cases where there is no change in meaning. According to this, reanalysis does not provide an explanation for the change itself, but theoretically serves as constraint. That is, the fact that a reanalysis could appear, due to two available syntactic analyses $\left(G_{1}\right.$ and $\left.G_{2}\right)$ - a new linguistic form $\left\{G_{2}, M_{1}\right\}$ has been created.

This begs the question of what prompted the change. Obviously, one possibility is that such changes occur at random when suitable conditions exist (both $G_{1}$ and $G_{2}$ are available). But it is nevertheless worth noting that this change may be a private case of a more general phenomenon. The change under discussion transforms a complex bi-clausal structure (a conditional sentence with a condition and consequence) into a simpler, uni-clausal structure with a prepositional phrase. In other words, this is a case of structural simplification, and it has long been noted that a wide range of syntactic changes are characterized by paradigmatic simplification of precisely this sort (e.g. Harris and Campbell 1995, Givon 1991 and Grossman 2009). For our purposes it is significant that this structural change was not attended by any semantic change (see Bar-Asher Siegal \& De Clercq (2019), for a similar phenomenon). It is likewise significant that the reverse phenomenon, of a uni-clausal structure transforming into a bi-clausal one, is not observed in diachronic langauge change. Hence, the historical transformation of 'ilmale from a conditional 
marker into a preposition may stem from general principles that motivate the transformation of grammatical structures into alternative structures with identical meaning, among them the principle of structural simplification (see also Roberts 1993, Roberts \& Roussou 2003 and Van Gelderen 2010).

5. A two-stage semantic change. Following the reanalysis discussed in the previous section, which was purely structural, 'ilmale underwent a semantic change, apparently in two stages: (1) the addition of expletive negation; (2) the semantic reanalysis of the expletive negative element as an meaningful negative element.

According to the analysis suggested here, the semantic process that changed the meaning 'ilmale - by transforming it from an expression that includes a negative component ("if not") into a marker of counterfactual condition alone - was preceded by a process that added a linguistic component to the existing expression. Interestingly, Harris and Campbell (1995: 7225) observed that exploratory expressions, i.e., elements added to existing expressions (without changing the truth conditions), very often undergo reanalysis. The section below examines this two-stage change and discusses it in light of the broader questions regarding reanalysis.

5.1 EXPLETIVE NEGATION. According to the analysis described above, the semantics of 'ilmale originally included a negative morpheme. 'ilmale was therefore restricted to NCCs, since the addition of an overt negative element would have resulted in a double negative. Although double negation is often possible, and yields the equivalent of a positive proposition (9), it is unavailable in counterfactual conditionals, as discussued in Bar-Asher Siegal (2015b) and shown in (10).

(9) He didn't not come (= he came).

(10) * Had he not not come, I would have been happy (=had he come, I would nave been happy).

Despite this, from a certain period onward, the sequence 'ilmale + NEGATOR (lo in Hebrew and $l \bar{a}$ in Aramaic) appeared, and was not interpreted as a double negative. Its meaning was identical to that of 'ilmale: both meant "if not". In other words, the number of meaningful morphemes was identical in both expressions, for the negators $l o$ and $l \bar{a}$ contributed nothing to the semantics. In the Tannaitic period, we find both variants, both of them with a negative meaning, as shown in (11) and (12): ${ }^{6}$
a. $r a^{\prime} u y$
racuy
haya
Ezra
še-tinaten
torah
suitable
be.PST.3.M.SG Ezra
REL-give.PASS.FUT.3.F.SG
Tora
'al=yad-o 'ilmale qidem-o
moše
by-3.M.SG 'ilmale come.before.PST.3.M.SG-ACC.3M.SG
Moses
"Ezra was suitable for the Torah to be given (to Israel) by him, had Moses not come first" (Tosefta, Sanhedrin 4:7)
b. 'ilmale lo hizziq-o
ilmale NEG injur.PST.3.SG-ACC.3.M.SG be.3.M.SG worth šmone me-ot zuz
eight hundred-PL zuz
"If [the belligerent ox] had not injured [the other ox], the value [of the latter] would have now stood at eight hundred dinars". (Tosefta, B. Qama 3:5)

\footnotetext{
${ }^{6}$ Breuer (1987) was the first to note that this phenomenon, but proposed a different analysis for it.
} 
The phenomenon of semantically null negative elements is a common one, and has been given various names, such as expletive, pleonastic, superfluous and paratactic negation (Abels 2005, Krifka 2010, Makri 2013, inter alia). In French, for example, the verb peur, meaning 'be afraid' (in the sense of being worried), with a clausal complement, can occur (optionally) with expletive negation:

(12) J'ai peur qu'il (ne) pleuve.

'I'm afraid it is going to rain'

Similar instances of 'ilmale lo are found in Modern Hebrew as well. ${ }^{7}$ The example in (13) includes an instance of 'ilmale lo, followed by an instance of 'ilmale, both of them meaning "if not".

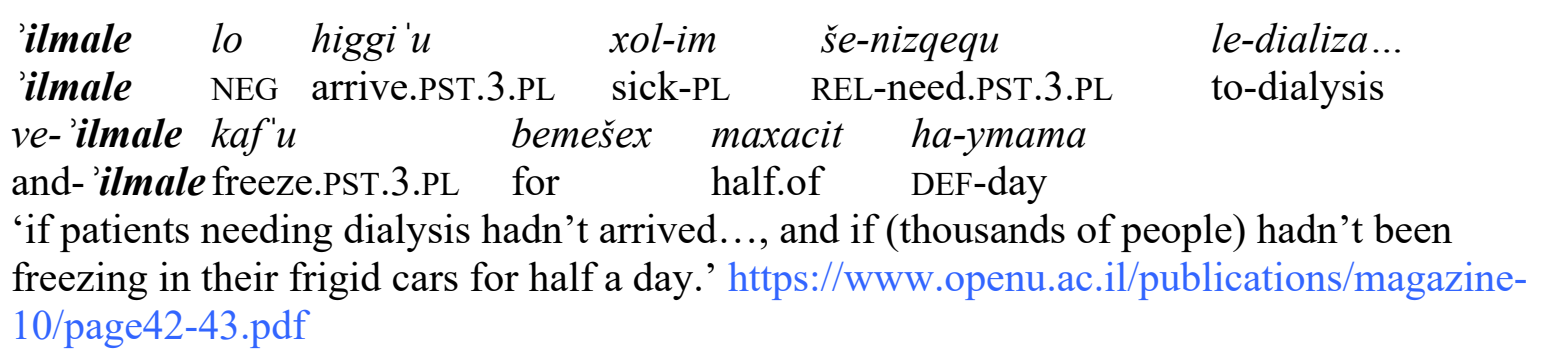

As stated, expletive negation is a general phenomenon observed cross-linguistically. To understand why it occurs with 'ilmale, let us address the question of why it occurs at all, and the more fundamental question of whether it is a random phenomenon. In other words, can semantically null negatives appear anywhere, or do they tend to appear in particular environments? And if the latter is the case - which seems likely - do NCCs belong to the category of environments that trigger expletive negation, and if so, why?

Expletive negation (EN) has been widely discussed, from both a syntactic and a semantic perspective, and this is not the place to elaborate on its numerous aspects. For our purposes, it is sufficient to note that Jin \& Koenig (2019, forthcoming) have shown, based on a typological review of 700 languages, that the phenomenon is not random. Rather, it is largely restricted to specific environments, which have the following feature in common: they involve a situation where both a proposition and its negation are cognitively salient, causing speakers to utter the negative sentence instead of the positive one. In other words, they contend that, at least at first, this is not a matter of grammar (competence) but rather of production (performance). In their words:

"A speaker intends to say $p$, but because $\neg p$ is strongly activated by the meaning of a trigger, $\neg p$ is produced. Furthermore, because $p$ and $\neg p$ are typically entailed (but relative to distinct sets of worlds or time intervals...) by the meaning of EN-triggers, the likelihood of occurrence of EN is higher than for other kinds of inferences." (Jin \& Koenig 2019: 164)

Let us illustrate this claim with NCCs headed by 'ilmale. Given Jin \& Koenig's insights, the appearance of expletive negation in this context is not at all surprising, since such sentences

\footnotetext{
${ }^{7}$ In this context Modern Hebrew resembles the early Tannaitic stage, which preceded the Babylonian Talmud (BarAsher Siegal 2019). This cyclicity in the historical development of Hebrew, i.e., the return to earlier stages, is due to the unique status of Medieval Hebrew in the history of the language and to processes and conditions peculiar to the revival of Hebrew. See Bar-Ziv Levy (in print) on counterfactual markers.
} 
presuppose that the proposition expressed by the condition is not true. Consider example (12) again (now only in its English translation):

(14) If [the belligerent ox] had not injured [the other ox], the value [of the latter] would have now stood at eight hundred dinars.

This conditional sentence divides the set of possible worlds into those in which $p$ is true and those in which $\neg p$ is true (where $p=Y$ injured $X$ ):

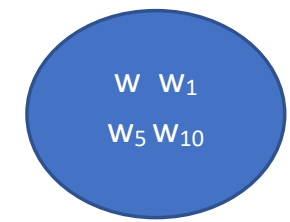

The set of worlds in which $\mathrm{p}$ holds [the value of $y$ is less than 800 dinars]

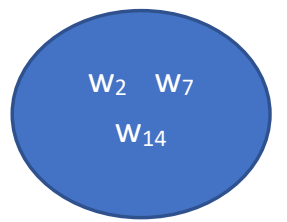

The set of worlds in which $\mathrm{p}$ does not hold [the value of $y$ is at least 800 dinars]

Figure 3. The division of possible worlds

In other words, counterfactual conditionals generally divide the set of possible worlds into two subsets, those in which the condition is true and those in which the condition is false, and make an assertion regarding the validity of the consequence in each subset, meaning that both the condition and its negation are salient in the speaker's mind. These conditionals thus certainly seem to belong to the category of contexts which, according to Jin \& Koenig's analysis, may trigger expletive negation. It is, therefore, quite easy to imagine a situation where 'ilmale gave rise to expletive negation, producing the semantically equivalent expression ilmale lo. As shown by example (13) above, a parallel development occurred in Modern Hebrew as well.

5.2 ClARIFICATIONS ABOUT EXPLETIVE NEGATION. Having shown that (negative) counterfactual conditionals are a natural environment for the emergence of expletive negation, I would like to address three additional issues.

5.2.1. COMPETENCE VS. PERFORMANCE. Jin \& Koenig show that speakers often produce spontaneous instances of expletive negation, i.e., "slips of the tongue" that contravene the grammatical rules of the language. They show that the environments that tend to trigger such slips of the tongue are the same environments that, in other languages, feature grammaticalized cases of expletive negation. Accordingly, they suggest that expletive negation arises in spontaneous speech (performance), but subsequently may become part of the grammar of the language (competence), to varying degrees: the negative element may become licit (i.e., optional) in a given construction. Alternatively, it may even become compulsory, although it is semantically redundant.

ilmale sentences in Modern Hebrew seem to exhibit the first stage, where the expletive negative is possible but not compulsory. This explains why we find examples of both 'ilmale and 'ilmale lo (sometimes even in the same sentence, as shown in (13)). Below, I will argue that, earlier in the history of Hebrew and in Aramaic, a process of grammaticalization occurred whereby expletive negation became mandatory with 'ilmale.

5.2.2. DesignATED NCC MARKERS. Why do we find expletive negation in 'ilmale conditionals, but not in counterfactual conditionals that feature an overt (non-expletive) negative element ('If I 
had not... then...')? This possibly follows from the unique semantics of 'ilmale. Studies have shown that counterfactual conditions introduced by an unmarked conditional marker (e.g. if in English) differ from conditions that feature designated markers of NCC (such as Hebrew 'ilmale). Counterfactual conditionals generally convey that the condition and the consequence are both false in the real world. ("If I hadn't come to the game, we would have lost" $\rightarrow$ I did come to the game, and we won). However, this is not a logical (or lexical) entailment, but rather an implicature, and as such it can be cancelled (Andersen 1957, Stalnaker 1975). But when the NCC is introduced by a dedicated linguistic marker, the falsity of the condition is a presupposition, which cannot be cancelled (Henderson 2010 and Ippolito \& Su 2014). In other words, only expressions like 'ilmale, which are designated NCC markers, necessarily make a statement about the real world. Thus, they divide the possible worlds into two sets, which differ in terms of the truth conditions of the condition and consequence. According to the analysis of Jin \& Koenig, this is precisely the environment where expletive negation is expected.

5.2.3. THE SCOPE OF THE PHENOMENON: Naturally, 'ilmale triggered expletive negation only when it functioned as a clause-initial conditional marker, not as a preposition meaning 'without', for the emergence of expletive negation depends on the presence of a clause that is negated. Such a clause does not exist in the case of the preposition. This created an overt distinction between the environment where 'ilmale functioned as a conditional element and the one where it functioned as a preposition: only the former featured expletive negation. This last point is highly significant in our context. As suggested above, the next stage in the evolution of 'ilmale involved a change in the semantics of this form, transforming it from an NCC marker into a marker of counterfactual condition unspecified for polarity. This particular change, too, could only feasibly affect the 'ilmale that functioned a conditional marker, not the variant that functioned as a preposition. Let us now describe this semantic shift.

5.3 THE SEMANTIC REANALYSIS. Initially, 'ilmale was interpreted as negative independently of whether accompanied by the (expletive) negative element lo/la. . Over time, it appears that a semantic reanalysis occurred: the expletive negator came to be seen as the source of the negative meaning, whereas 'ilmale itself came to be seen as an expression of counterfactual condition, unmarked for polarity (cf. Ben Haim 1952-3). Once understood in this manner, 'ilmale could introduce either a PCC (15a) or an NCC negated by lo/lā (15b).
a. 'ilmale 'ani
hay $w$-hu
met
'ilmale $1 . \mathrm{SG}$
alive and-3.M.SG dead

If I were alive and he were dead...' (Babylonian Talmud, Berakhot, 27b).

$\begin{array}{lll}\text { b. } \quad \text { ilmale lo nictanenu } & \text { gehaāl-im.. } \\ & \text { ilmale NEGcool.PST.3.PL } & \text { ember-PL }\end{array}$

"If it were not for the fact that the embers cooled" (Babylonian Talmud, Yoma, 67a).

The process described here is one of semantic reanalysis. The same sequence ('ilmale lo) was initially understood as containing a bound negative morpheme (within the word 'ilmale itself) and lacking an independent negative element, except for the expletive $l o$. In the next stage this sequence was reanalyzed as a conditional element unmarked for polarity, followed by a semantically-meaningful negator.

Why did this semantic reanalysis occur? Some would object that this is not a legitimate question, namely, that reanalysis may occur whenever there are two possible analyses for the same form, and that its actual occurrence or failure to occur is just a matter of accident. 
However, it is difficult to imagine a reverse case of reanalysis, in which a meaningful negative element is reanalyzed as an expletive one. It therefore seems reasonable to posit that another general principle is at play here: a cognitive-semantic principle that prefers an analysis in which every overt element contributes to the meaning. Given such a principle, expletive negation is likely to undergo reanalysis as meaningful negation, but not vice versa. It is important to mention that semantic reanalysis is not the fate of all expletive negative elements. In order for it to occur, it is required that the original form already contained a bound negative morpheme.

It is also important to note that the reanalysis of the sequence 'ilmale lo produced no difference in the overall meaning of this sequence or in the truth conditions of the proposition containing it. Whether the negation was taken to derive from the word 'ilmale itself or from the following lo, the clause as a whole was understood as an NCC. However, the reanalysis gave rise to sentences containing 'ilmale without lo that were understood as positive counterfactual conditionals. This is the actualization stage of the reanalysis. ${ }^{8}$ In other words, changes in truthvalues of propositions occurred only at the actualization and extension stages of reanalysis. This is an important point, which will be addressed again in the conclusion.

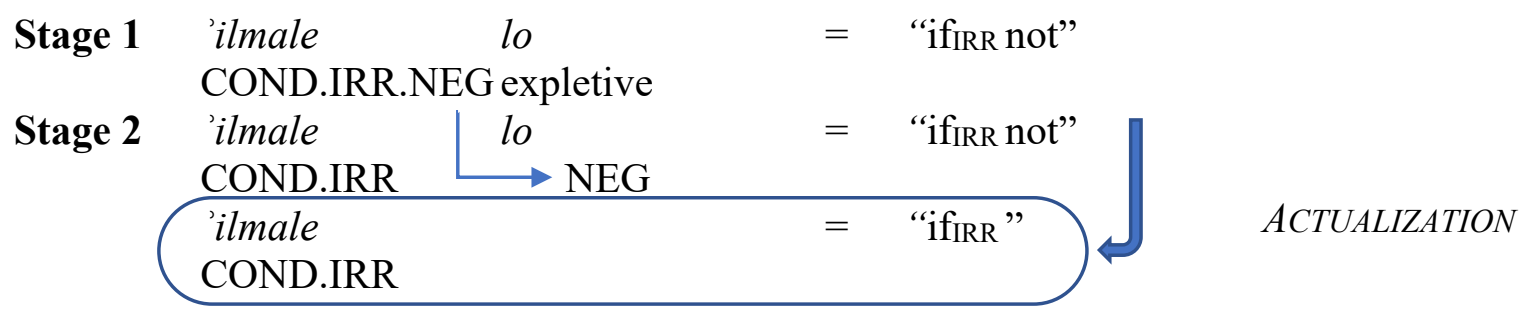

Figure 4. Semantic reanalysis of 'ilmale

The reanalysis described here may involve another, secondary, change in the meaning of 'ilmale. Comparative semantic studies have shown that NCCs generally convey a strong (biconditional) relation of "if and only if", whereas PCCs do not necessarily convey this strong conditionality (Henderson 2010, Ippolito \& Su 2014). Given this generalization, we would expect to find that 'ilmale in positive contexts will have the weaker meaning. This prediction is apparently borne out: among the instances of ilmale in the Talmud, only in positive contexts do we find instances where "if and only if" is not implied, such as the following:

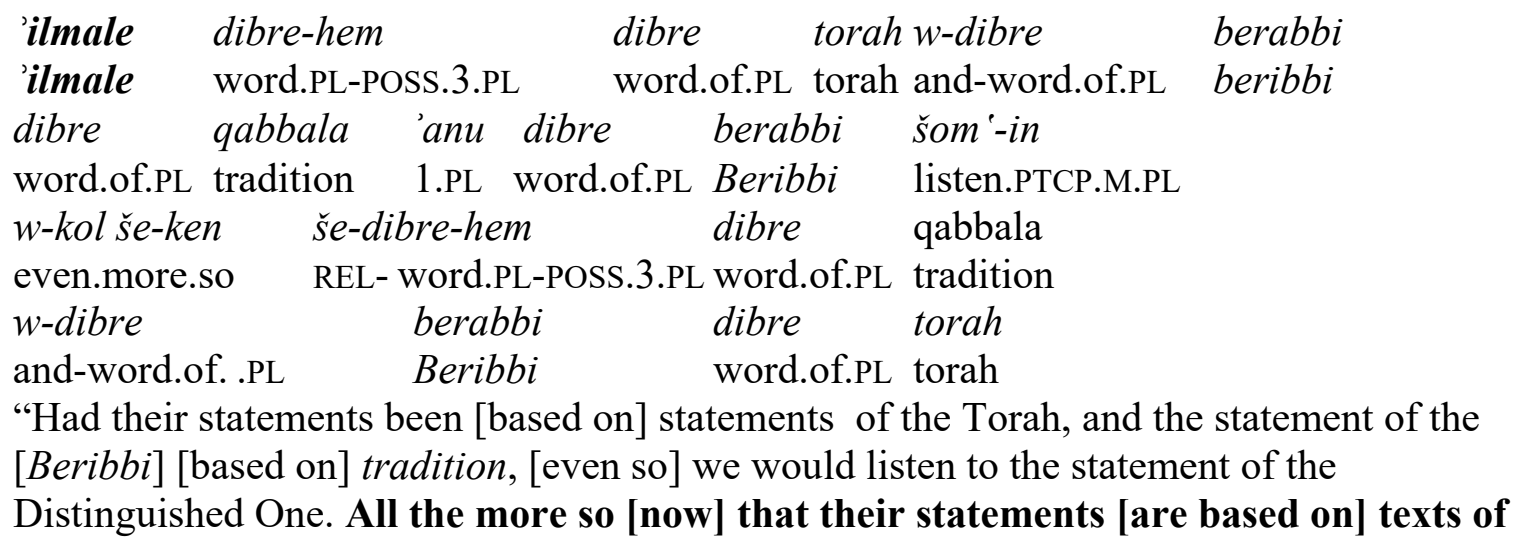

\footnotetext{
${ }^{8}$ In this context I adopt Harris and Campbell's (1995) definition of the term "actualization". See Andersen (2001a) for a review of the literature on this concept.
} 
the tradition, while the statement of the Distinguished One is [based on] the statements of the Torah" (Babylonian Talmud, Hullin 137b).

The phrase in bold shows that the relation here is not a strong one, because it explicitly states that the consequence would be true even if the condition was false. The loss of the strong conditional meaning, if it indeed occurred, conforms to a cross-linguistic distinction between NCCs and PCCs. This shows that changes motivated by language-specific factors are nevertheless subject to universal semantic constraints, and thus that semantic reanalysis is indeed subject to universal considerations and possibilities.

However, an examination of the entire Babylonian Talmud corpus ${ }^{9}$ suggests that, even in positive contexts, 'ilmale still carries a strong inference that both the condition and consequence are false in the real world (although, in the case of a historical language, it is obviously difficult to know whether the inference is cancelable or not). In other words, this inference, crosslinguistically associated with NCCs, seems to be retained by 'ilmale even in its new, nonnegative interpretation. If this is indeed the case, it is another example of reanalysis giving rise to a unique linguistic phenomenon, presumably because reanalysis is very limited in the extent of the semantic change it can produce. But this issue obviously requires further research.

6. Solving the puzzle. The analysis presented above provides an answer to the puzzle with which we began: Why is it that, in the Hebrew and Aramaic of the Babylonian Talmud, ilmale is negative when preceding a noun but positive in clause-initial position (2-3)? The proposed reanalysis of 'ilmale depends on the emergence of expletive negation at an earlier stage. It is this expletive element that underwent the initial reanalysis, changing from a semantically null element into an actual negator. However, this process could only take place in clauses, which denote a proposition that can be negated. Hence, it applied only to cases where 'ilmale functioned as a conditional marker. In cases where 'ilmale functioned as a preposition meaning 'without', the expletive negation did not appear, and obviously could not undergo reanalysis. 'ilmale in these contexts therefore remained unaffected. This analysis yields the synchronic distribution presented above in examples 2-3.

7. Summation and conclusions about reanalysis. As we saw, it is important to keep in mind that there are different kinds of reanalysis. Sometimes the change is confined to the grammatical level, and sometimes it is confined to the semantics (and to syntactic changes triggered by the semantic ones). The transformation of ilmale from a clause-initial conditional marker into a preposition was a purely grammatical change that did not affect its meaning. In fact, it is the semantic identity of the two syntactic constructions (the input and output of the reanalysis process) that presumably facilitated the reanalysis in the first place.

It is important to note that the subsequent semantic reanalysis of 'ilmale likewise involved no change in the truth conditions in the broader environment, in the initial stage. The truthconditional change occurred only when the reanalysis was actualized by applying it to 'ilmale in other contexts. This leads me to propose the broad principle in (17):

(17) The reanalysis of a form $F$ does not change the truth conditions of the proposition $P$ that contains it, whether the reanalysis is on the grammatical level $(G)$ or on the semantic level $(M)$.

In the case of syntactic reanalysis, the truth conditions remain identical or near-identical.

${ }^{9}$ For a description of the corpus on which the present study relies, see Bar-Asher Siegal (2019). 
In the case of semantic reanalysis, the truth conditions of the specific proposition which undergoes reanalysis remain unchanged, but reanalysis generates other propositions, in which actualization takes place, whose truth conditions are no longer the same.

The validity of these generalizations should be examined in future comprehensive studies of reanalysis. Let me conclude with two further observations:

1. The ability to identify environments where reanalysis took place is a necessary requirement for explaining historical processes of language change. In all the analyses presented in this paper, the phenomenon of reanalysis itself did not provide the explanation or the motivation for the historic change, but only constituted a constraint: the analyses defined the environments where the change could occur.

2. Historical processes involving reanalysis produce "strange beasts", unique in the inventory of linguistic forms - such as a preposition that, in terms of its semantic content, means "without" but is restricted to environments carrying an implicature associated with NPPs. The emergence of such innovations may arise from a principle of minimizing change. This is pertinent to the question of how the new interpretations arise. The creation of "strange beasts" assumes that the process is local, and is unrelated to the semantics of other salient expressions. But at the same time, as we saw, there are also universal factors at play, without which it is impossible to explain the full range of changes. The fact that 'ilmale conveys the logical relation of "if and only if" in its negative interpretation, but not in its positive one, is part of a universal phenomenon. Similarly, the fact that NCCs (with a designated conditional marker) give rise to expletive negation is likewise related to a general phenomenon, involving a strong presupposition that the condition does not hold in the real world.

\section{References}

Abels, Klaus. 2005. Expletive negation in Russian: A conspiracy theory. Journal of Slavic Linguistics 13. 5-74.

Andersen, Henning. 1973. Abductive and deductive change. Language 49. 765-93.

Andersen, Henning. 2001a. Introduction. In Henning Andersen (ed.), Actualization: Linguistic change in progress. 1-19. Amsterdam: John Benjamins0

Andersen, Henning. 2001b. Actualization and (uni)directionality. In Henning Andersen (ed.), Actualization: Linguistic change in progress. 225-248. Amsterdam: John Benjamins.

Anderson, A.R. 1957. A theory of subjunctive conditionals. The Journal of Symbolic Logic 22. 30.

Bar-Asher, Elitzur A. 2009. Theory of argument realization and its applications to features of the Semitic languages. Cambridge, MA: Harvard University dissertation.

Bar-Asher Siegal, Elitzur A. 2011. From typology to diachrony: Synchronic and diachronic aspects of predicative possessive constructions in Akkadian. Folia Linguistica Historica 32. 43-88. https://doi.org/10.1515/flih.2011.003.

Bar-Asher Siegal, Elitzur A. 2015a. The case for external sentential negation: Evidence from Jewish Babylonian Aramaic. Linguistics 53. 1031-1078. https://doi.org/10.1515/ling-2015-0025.

Bar-Asher Siegal, Elitzur A. 2015b. Arguments in favor of an ambiguist approach. Paper presented at the Göttingen workshop on negation and polarity, September 2015.

Bar-Asher Siegal, Elitzur A. 2019. The history of the forms 'ilule and 'ilmale - Part I: linguistic diachrony. Leshonenu 81. 95-115. 
Bar-Asher Siegal, Elitzur A. 2020a. The history of the forms 'ilule and 'ilmale-Part II: textual transmissions. Leshonenu 82.60-78.

Bar-Asher Siegal, Elitzur A. 2020b. The NP-Strategy for expressing Reciprocity: Typology, History, Syntax and Semantics, John Benjamins Publishing.

Bar-Asher Siegal Elitzur A. \& Karen De Clercq. 2019. From negative cleft to external negator. In Miriam Bouzouita, Anne Breitbarth, Lieven Danckaert \& Elisabeth Witzenhausen (eds.), Cycles in language change. 228-248. Oxford: Oxford University Press.

Bar-Ziv Levi, Miri. Forthcoming. Regularization in the crystallization of Modern Hebrew: The case of negative counterfactual conditionals. Leshonenu.

Ben-Haim, Ze'ev. 1952-3. keisad ništameš be-millat 'ilmale?. Leshonenu 18. 27-30.

Breuer, Y. 1987. On the Hebrew Dialect of the Amoraim in the Babylonian Talmud. Language Studies 2-3: 127-153.

Brockelmann, Carl. 1913. Grundriss der vergleichenden Grammatik der semitischen Sprachen II: Syntax. Berlin: Reuther \& Reichard.

De Smet, Hendrik. 2009. Analysing reanalysis. Lingua 119. 1728-1755. https://doi.org/10.1016/j.lingua.2009.03.001.

De Smet, Hendrik. 2014. Does innovation need reanalysis? In Evie Coussé \& Ferdinand von Mengden (eds.), Usage-based approaches to language change. 23-48. Amsterdam: John Benjamins.

Eckardt, Regine. 2006. Meaning change in grammaticalization: An enquiry into semantic reanalysis. Oxford: Oxford University Press.

Felser, Claudia. 2017. Syntactic ambiguity in real-time language processing and diachronic change. In Marianne Hundt, Sandra Mollin \& Simone Pfenninger (eds.), The changing English language: Psycholinguistic perspectives (Studies in English Language). 271-291. Cambridge: Cambridge University Press. https://doi.org/10.1017/9781316091746.

Francez Itamar. 2007. Existential propositions. Stanford, CA: Stanford University dissertation.

Francez Itamar. 2009. Existentials, predication, modification. Linguistics and Philosophy 3. 1-50. https://doi.org/10.1007/s10988-009-9055-4.

Garrett, Andrew. 2012. The historical syntax problem: Reanalysis and directionality. In Dianne Jonas, John Whitman \& Andrew Garrett (eds.), Grammatical change: Origins, nature, outcomes. 52-72. Oxford: Oxford University Press. https://doi.org/10.1093/acprof:oso/9780199582624.001.0001.

Givón, Talmy. 2001. Syntax: An introduction, vol. 2. Amsterdam \& Philadelphia: John Benjamins.

Grossman, Eitan. 2009. Periphrastic perfects in the Coptic dialects: A case study in grammaticalization. Lingua Aegyptia 17. 81-118.

Harris, Alice C. \& Lyle Campbell 1995. Historical syntax in cross-linguistic perspective. Cambridge: Cambridge University Press.

Henderson, Robert. 2010. If not for counterfactuals: Negating causality in natural language. WCCFL 28 Online Proceedings. https://sites.google.com/site/wccfl28pro/henderson.

Ippolito Michela \& Julia Su. 2014. Counterfactuals, negation, and polarity. In Luka Crnic \& Uli Sauerland (eds.), The art and craft of semantics: A festschrift for Irene Heim, vol. 1 (MIT Working Papers in Linguistics 70). 225-243.

Jastrow, Marcus. 1885. Ilule, ilmale et alima. Revue des études juives 11. 157-158.

Jin, Yin \& Jean-Pierre Koenig. 2019. Expletive negation in English, French, and Mandarin: A semantic and language production model. Empirical Issues in Syntax and Semantics 12. 157186. 
Jin, Yin \& Jean-Pierre Koenig. Forthcoming. A cross-linguistic study of expletive negation. Linguistic Typology.

Kiparsky, Paul. 2012. Grammaticalization as optimization. In Dianne Jonas, John Whitman \& Andrew Garrett. (eds.), Grammatical change: Origins, nature, outcomes. 15-51. Oxford University Press. https://doi.org/10.1093/acprof:oso/9780199582624.001.0001.

Krifka, Manfred. 2010. How to interpret 'expletive' negation under bevor in German. Studia Grammatica 72. 214-236. https://doi.org/10.1524/9783050062365.214.

Lambert, M. 1880. ð et $p$. Revue des études juives 9. 290-301.

Langaker, Ronald. 1977. Syntactic reanalysis. In Charles N. Li (ed.), Mechanisms of syntactic change. Austin, TX: University of Texas Press.

Madariaga, Nerea. 2017. Reanalysis. In Adam Ledgeway \& Ian Roberts (eds.), The Cambridge handbook of historical syntax. 70-91. Cambridge: Cambridge University Press.

Makri, María Margarita. 2013. Expletive negation beyond Romance. Clausal complementation and epistemic modality. York, UK: University of York MA thesis.

McDaniels, Todd. 2003. What's wrong with reanalysis? Toronto Working Papers in Linguistics 21. 81-88. https://twpl.library.utoronto.ca/index.php/twpl/article/view/622.

Rabin, Chaim. 2000. The development of the syntax of Post-Biblical Hebrew. Leiden: Brill.

Roberts, Ian. 1993. Verbs and diachronic syntax: A comparative history of English and French. Dordrecht: Kluwer.

Roberts, Ian \& Anna Roussou. 2003. Syntactic change. A minimalist approach to grammaticalization. Cambridge: Cambridge University Press.

Segal, Moshe Z, 1932. Conditional clauses in Biblical and Tannaitic Hebrew. Leshonenu 4. 191211.

Stalnaker, Robert. 1975. Indicative conditionals. Philosophia 5. 269-286. https://doi.org/10.1007/BF02379021.

Timberlake, Alan. 1977. Reanalysis and actualization in syntactic change. In Charles N. Li (ed.), Mechanisms of syntactic change. 141-77. Austin, TX: University of Texas Press.

Traugott, Elizabeth Closs \& Robert Dasher. 2002. Regularity in semantic change. Cambridge: Cambridge University Press.

van Gelderen, Elly. Features in reanalysis and grammaticalization. In Elizabeth Traugott\& Graeme Trousdale (eds.), Gradience, gradualness and grammaticalizatian. 129-147. Amsterdam: John Benjamins. 